tions, illumination of the actual ground, and fixed illuminated signs to show the position of wind, etc. At Croydon the lighting of high wireless masts, which form dangerous obstructions, has been effected by placing Iooo-c.p. gas-filled lamps, screened red, on the top of the masts. These form a good recognition mark.

Ground illumination requires special care to avoid dazzling the eyes of pilots at some angles. A special arrangement recommended at the International Air Convention is the use of lights arranged in the form of two "L's" to indicate positions for "taking off" and landing. Such lights were originally mounted in reflectors covered by flat glass discs in such a way that they were readily visible from above, but invisible at close range. Better methods of diffusion, enabling lights to be seen at all angles, have since been devised. Searchlights appear helpful, but have to be used with care to avoid confusing shadows when the machine is near the ground. An appendix to the paper contains particulars of the recommendations of the International Air Convention in regard to signals of distress, etc. Much has yet to be done in this new field, but the paper affords a useful review of existing procedure.

\title{
The Preservation of Stone.
}

AECTURE to the Royal Society of Arts on the
above subject by Mr. Noel Heaton is published in the Journal of the society for December 30 last. The lecturer gave an account of the various attempts which have been made to solve the important problem of preventing the decay and disintegration of stonework in buildings. The great majority of modern stone buildings, and a still greater proportion of medieval buildings, are constructed of limestone or sandstone, and the problem centres around these varieties rather than about the more resistant granite, used only to a limited degree. The causes of disintegration may be natural, depending on fluctuations of temperature, on rain, on erosion by wind, and, in ferruginous sandstones, on oxidation. Minute differences in structure often cause great differences in durability. The growth of vegetation on stone usually hastens decay. The most potent cause of decay is, however, the " unnatural " action of sulphuric acid, derived from coal-smoke, coupled with the accumulation of soot and grime. Sir Frank Baines, who introduced the lecturer, stated that, roughly, 80 ,ooo tons of sulphuric acid are thrown annually into the London atmosphere. Strain set up by the rusting of iron is also a contributory cause of decay. The lecturer then turned to the means of preventing decay.

An indirect method of preventing decay is to further, by every possible means, the campaign against atmospheric pollution. The stone may be treated with preservatives, which were divided into three groups: (a) those acting merely as surface coatings; (b) those impregnating the stone without chemical action; and $(c)$ those operating by chemical reaction with the stone. In the first class are paint and limewash, the latter being useful where the stone is subjected to a moist atmosphere, but protected from rain. In the second class are mineral wax applied by heat or in solution in benzene, drying oils, creosote, or gelatinous precipitates formed on the stone. The first process is very old, and is effective for certain purposes. Treatment with alum solution, followed by soft soap, which results in the precipitation of an aluminium salt of the fatty acids, is recommended.

In the third class treatment with baryta is effective in repairing a stone disintegrated by sulphuric acid. A common method is the deposition of silica or silicates. Treatment with waterglass leads to unsightly efflorescence. This may be reduced by treating with a solution of arsenic acid after the waterglass, but the most satisfactory results are obtained with silicofluorides, introduced in France by Kessler in 1883 . A solution of magnesium silicofluoride reacts with limestone :

$$
\mathrm{MgSiF}_{6}+2 \mathrm{CaCO}_{3}=\mathrm{SiO}_{2}+\mathrm{MgF}_{2}+2 \mathrm{CaF}_{2}+2 \mathrm{CO}_{2} .
$$

The solution, known as "Fluate," is manufactured in France, and the lecturer stated that, although the results were conflicting, it appeared to be beneficial. In America the double salts of magnesium and zinc were preferred. The use of the solution has recently been investigated by Prof. Desch, in conjunction with the Department of Scientific and Industrial Research, and, although the detailed results have not yet been published, the conclusions appear to be that too strong a solution should not be used (not stronger than Io per cent.), and that the mode of application should be adjusted to particular conditions. The method is most useful on new work. The use of nostrums of unknown composition is strongly condemned, as they may cause great injury. Sir Frank Baines also contributed some valuable information in the discussion on the lecture.

\section{Mathematics in Japan.}

A GOOD many years ago there was an exhibition at Earl's Court in which the Japanese Government and nation took a conspicuous part. For several reasons the Japanese art section was particularly interesting. It contained priceless and authentic specimens of their national painting and handicraft before they were influenced by foreign methods and ideals. Besides this, there were paintings by some of their modern artists who adopted Western methods and conventions. The contrast was very striking, and in some respects not very satisfactory.

Similar reflections are suggested by the present state of Japanese mathematics, as shown, for example, in various mathematical papers recently received from the University of Tokyo. Circumstances are different because mathematical science is now cosmopolitan, and no single nation can afford to neglect its various developments. At the same time, like nationality in drinks, there is a kind of nationality in science, art, or any other human activity, which is justifiable, and even instructive, if it is not carried to excess. We may notice it, for example, in the papers and treatises of the leading mathematicians, such as Klein and Dedekind on one hand and Poincaré, Hermite, and Darboux on the other. The elegance of the best French text-books is scarcely equalled, if at all, by those of any other nation; at the same time, the corresponding German works are distinguished by thoroughness, method, and fulness of references. The treatise on elliptic modular functions by Klein and Fricke and Poincaré's memoirs on Fuchsian functions illustrate the point.

It is difficult to be sure how far Japanese mathematics is entirely original. They had various approximations to $\pi$, some of which, at any rate, seem to have been of their own invention. They had an extraordinary gift for solving numerical equations of high degrees by approximation, and one Japanese writer appears to have anticipated many of Steiner's 
theorems on poristic systems of circles. Besides this, they discussed elegant problems more or less suggested by familar objects, such as fans, toys, etc.

It would be a pity if all truly Japanese characteristics were to become obliterated. Apart from asthetic considerations, if they avoid falling into the rut of Western methods there is a chance of their producing something really novel and suited to their genius. They might, for instance, solve some of the outstanding problems of group theory or make some notable advance in Diophantine analysis--a subject which seems to have lost its fascination for most European mathematicians.

The attitude of an individual towards foreign mathematics is sometimes peculiar, and even amazing. Not very long ago an English lady spending a holiday at Utrecht was introduced to an eminent Dutch mathematician. Having a mathematical friend in England, she asked the professor his opinion of English mathematicians. The answer was to the effect that their work was so strangely insular that he could not spare the time to make himself familiar with it. This was after Cayley, Sylvester, and Salmon had published much of their best work on invariant theory.

G. B. M.

\section{University and Educational Intelligence.}

CAMBRIDGE.-In connection with the meeting of the Royal Agricultural Society at Cambridge in the coming summer, honorary degrees are proposed for H.R.H. Prince Albert, the President of the Society, Mr. C. R. W. Adeane, Sir Gilbert Greenall, Sir A. Daniel Hall, Mr. E. S. Beaver, Mr. A. E. Humphries, Mr. Ernest Mathews, and Mr. G. P. Hawkins.

An open Fellowship, for which all graduates of the University are eligible who took their first degree not earlier than June I9I9, is announced by King's College. Any one who wishes to offer himself as a candidate should communicate with the Provost as early as possible.

LEeds.-Prof. Sir Berkeley Moynihan has given to the University an endowment for the annual award at the Leeds Medical School of a gold medal to the best student of the year in Medicine and Surgery. In accordance with Sir Berkeley Moynihan's wish the gold medal will bear the name of William Hey in commemoration of the work of that great Leeds surgeon. The Council of the University in accepting the endowment have recorded their thanks to Sir Berkeley Moynihan for his generous gift. William Hey (I736-I8I9) was one of the pioneers of modern surgery. A brilliant operator and teacher, he established the tradition of surgical skill which has ever since been one of the chief distinctions of Leeds. $\mathrm{He}$ was a friend of Joseph Priestley when the latter was Minister of Mill Hill.

LONDON. - The following course of free public lectures is announced: At King's College, Strand, at 5.I 5 on Wednesdays, March 8, I5, and 22, "The Quantum Theory of Radiation and the Constitution of the Atom," Prof. Nils Bohr (in English)

THE bearing of improved means and methods of education receives striking confirmation in the figures adduced by $\mathrm{Mr}$. Percival Sharp in his address in January at the annual meeting of the Association of the Directors and Secretaries for Education held in the County Hall, London. Dr. Sharp submitted official statistics for England and Wales showing the curve of crime from 1870 , when the population of England and Wales was 22,000,00o, down to I919, when it had reached nearly $37,000,000$. In 1870 I07,62 I men and 39,604 women above sixteen years of age - a total of more than I 47,00o persons-were committed to prison. In I9I9 the numbers fell to 22,289 men and 87 I 8 women-a striking difference, having regard to the great increase in population. There are no figures available earlier than 1893 concerning indictable offences tried at the Quarter Sessions. The number of men convicted shrank in I919 to 5200 , as compared with 8200 in 1893 , whilst the number of women convicted declined from 1245 in 1903 to 826 in I919. The number of men tried summarily for indictable offences fell from 20,000 in 1893 to 16,000 in 1919 , and of women from 5000 to 3900 . The figures for non-indictable offences fell from $\mathrm{r} 33,000$ to 73,700 for men in the same years, and from 43,000 to I 8,000 for women. The Home Office has decided to close eight prisons and to shut down the female wings of six other prisons at the end of March next. So far as a great industrial and commercial area like Manchester is concerned, two large industrial and reformatory schools have recently been closed, and the returns available show that between 1907 and I92I the number of children under maintenance shrank from 659 in 1909 to 209 in I $92 \mathrm{I}$. These figures are conclusive as to the value and influence of education in the training of the children of the nation, and condemnatory of any proposed legislative measures of economy with regard to the restriction of such training. Rather they enforce the necessity for continued development and improvement.

A LIST of students from the King's Dominions overseas and from foreign countries studying in the universities and university colleges of the United Kingdom has been compiled by the Universities Bureau of the British Empire. The following figures gleaned from the list are of general interest, which would, however, be greatly enhanced if to them could be added statistics of the very numerous students from abroad who are studying at the Inns of Court, in other professional and technical institutions not included in universities and university colleges, and privately:- Of the total number, 4470, Asia contributed over a third ( I 576), Africa I I 87, America 78r, Europe 645, and the Pacific, 28I. Of the Asiatics 1240 are from India, Burma, and Ceylon; this includes 446 at London, I73 at Edinburgh, I7 I at Cambridge, I 70 at Oxford, and 65 at Glasgow. The Indian Students' Department of the Office of the High Commissioner in I92 I estimated that there were I 500 Indian students at the universities and technical colleges and 600 at the Inns of Court. From China came I 43, of whom 49 are at London, 25 at Edinburgh, and $x 7$ at Cambridge. Of 73 from Japan 55 are at London. South Africans and Rhodesians number 832 , including 327 at London, I 78 at Edinburgh, 95 at Dublin, 82 at Oxford, and 42 at Cambridge. Of 294 from Egypt, 88 are at London and $5^{2}$ at Birmingham. The U.S.A. contributed 400 , of whom 2 IO are at Oxford, a large proportion being Rhodes scholars. Of 200 from Canada, 87 are at Oxford. South America contributed 75 and the West Indies IOI, of whom 33 are at London and 23 at Edinburgh. Of the Europeans, $9 x$ are from Russia, 6I from Switzerland, 62 from France, 52 from Greece, 70 from Scandinavian countries, 49 from Rumania, and 48 from the kingdom of the Serbs, Croats, and Slovenes. Of 178 Australians, $5^{\circ}$ are at Oxford, $4^{\mathrm{I}}$ at London, 36 at Edinburgh, and 35 at Cambridge; while of IO2 New Zealanders, 27 are at London, 25 at Edinburgh, 24 at Cambridge, and 20 at Oxford. 